\title{
An Empirical Analysis of Port-City Relationship: Based on the Comparison of the Yangtze River Delta and the Pearl River Delta
}

\author{
Wei Chen \\ School of Economics, Jinan University, Guangzhou, China \\ Email: 727079493@qq.com
}

How to cite this paper: Chen, W. (2017) An Empirical Analysis of Port-City Relationship: Based on the Comparison of the Yangtze River Delta and the Pearl River Delta. Open Journal of Social Sciences, 5, 216-237.

https://doi.org/10.4236/jss.2017.55016

Received: April 7, 2017

Accepted: May 15, 2017

Published: May 18, 2017

Copyright $\odot 2017$ by author and Scientific Research Publishing Inc. This work is licensed under the Creative Commons Attribution International License (CC BY 4.0).

http://creativecommons.org/licenses/by/4.0/

\begin{abstract}
This paper first analyzes the status quo of the port-city relationship of the Yangtze River Delta and the Pearl River Delta through the relative concentration index. It is found that the port-city relationship of the Yangtze River Delta trends to be coordinated, while the port-city relationship of the Pearl River Delta is still in a state of uncoordinated. Then it analyzes the specific correlation between urban economy development and port development by gray relational analysis; it is found that the GDP and industrial output have high correlation with port cargo throughput, and the average correlation value of Yangtze River Delta is higher than that of the Pearl River Delta. Through the impulse response analysis, it is found that the urban GDP and industry have a significant effect on the development of the port in the short term, and the development of the port has no obvious influence on urban GDP and industry.
\end{abstract}

\section{Keywords}

Port-City Relationship, Relative Concentration Index, Gray Relational Analysis, Impulse Response Analysis

\section{Introduction}

Peace and development have become the theme of the world. Economy development is the primary task of the development of a country. With the unique geographical conditions, the port city has become an important node in the national and global economic circulation system. In recent years, China's major coastal port cities have developed rapidly. In the future, there are many ports needed to be built and the existing ports also need to be optimized.

Figure 1 and Figure 2 show the changes in GDP and port cargo throughput 


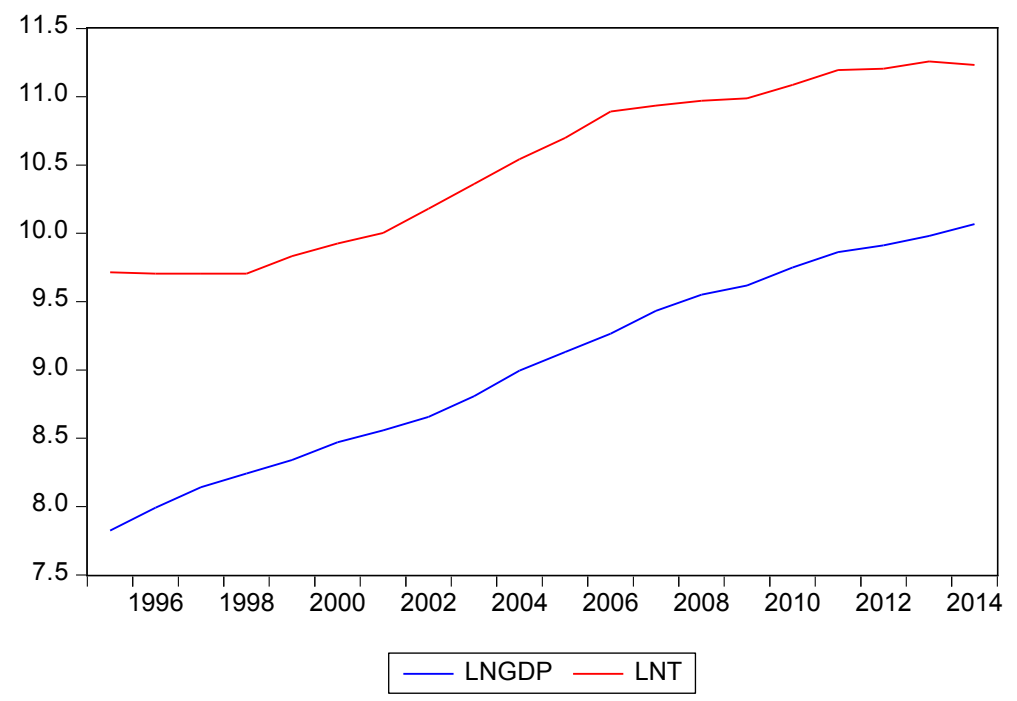

Figure 1. Changes of GDP and port cargo throughput in Shanghai Data Source: Yearbook of Each City.

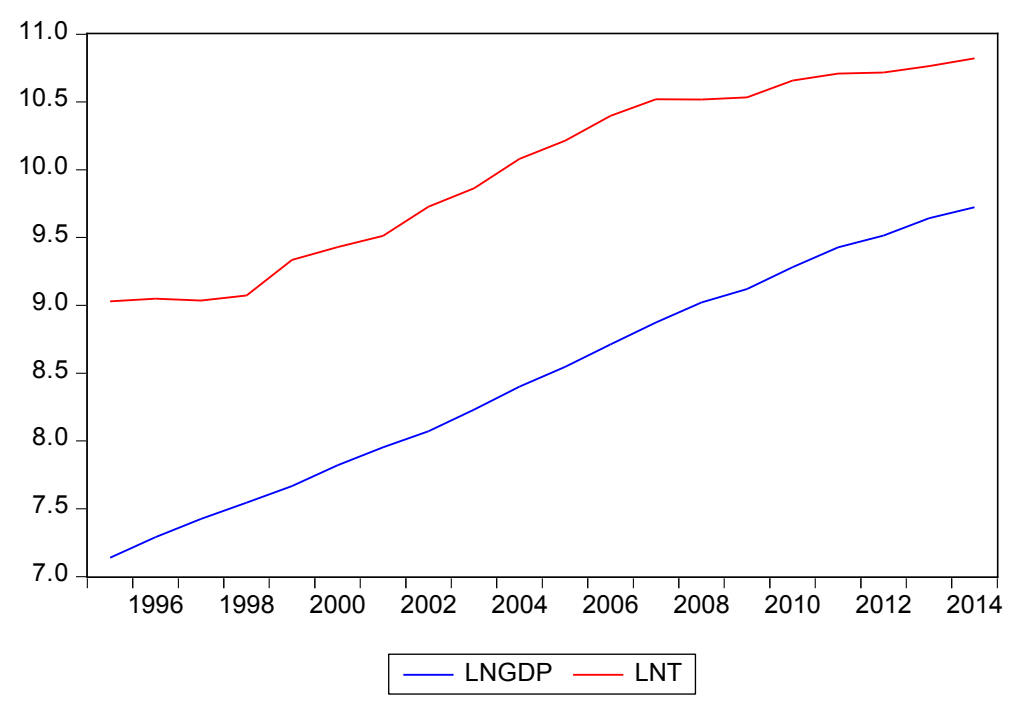

Figure 2. Changes of GDP and port cargo throughput in Guangzhou. Data Source: Yearbook of Each City.

(T) of Shanghai and Guangzhou in the period 1995 to 2014 (natural logarithmic processing of raw data). It can be seen from both figures, whether it is in Shanghai or Guangzhou, the city GDP and port cargo throughput have similar growth rate of change.

It can be inferred that there is a certain link between the urban economy development and port development, but how much is the correlation? Which specific aspects of the urban economy are related to port development? Does the urban economy development promote port development or the port development promote urban economy development? The purpose of this paper is to analyze the interaction between urban economy development and port development, the impact of urban economy development on port development, the impact of port development on urban economy development, and the specific 
aspects of the urban economy.

In this paper, we first use the relative concentration index to quantitatively analyze the port-city relationship of the Yangtze River Delta and the Pearl River Delta, and then we analyze the specific relationship between the urban economy development and the port through the gray relational analysis method. Based on the results of the gray relational analysis, we analyze the dynamic relationship of GDP and industrial output with the port cargo throughput, and analyze the empirical results.

\section{Relative Concentration Index (RCI)}

Relative concentration index (RCI) is used to measure the relative size of the port to the size of the city, Vallega (1979) first used the index to analyze the cities in the Mediterranean region to explore how the regional and population areas of the region were organized. Vallega found that the RCI of trade cities was higher than 1, while The RCI of the densely populated cities is less than 1, and the RCI of cities with close port size and city size is close to 1 [1]. Vigarie (1968) also used similar index to measure the country's dependence on the port (the number of tons of commercial maritime goods owned by each resident) [2]. Kenyon (1974) measured the importance of the transshipment function of the US port city relative to the size of the city (the tonnage of maritime goods owned by each resident) [3]. China's scholar Chen Hang (2009) first used the index to analyze the time series development characteristics of China's port city [4].

In this paper, the RCI is improved as follows: After analyzing the previous research methods. First, we use economy scale (GDP) to reflect the urban concentration instead of population scale, mainly because this study is about the relationship between urban economy development and the port development. The second is that we use port cargo throughput to reflect the port development instead of the container throughput, mainly because the port cargo throughput is more generally applicable to facilitate the comparison between different ports, and the data can be traced back to earlier. Third, taking into account the Yangtze River Delta and the Pearl River Delta port group also includes inland ports, so the object will be extended to the river port and harbor. Through the above improvements, $\mathrm{RCI}$ in this paper is calculated as:

$$
\begin{gathered}
P R_{i j}=P_{i j} / \sum_{i=1}^{n} P_{i j} \\
C R_{i j}=C_{i j} / \sum_{i=1}^{n} C_{i j} \\
R C I_{i j}=\frac{P_{i j} / \sum_{i=1}^{n} P_{i j}}{C_{i j} / \sum_{i=1}^{n} C_{i j}}
\end{gathered}
$$

In the formulas (1) to (3), $P_{i j}$ represents the port scale of port i (reflected by port throughput), $C_{i j}$ represents the city economy scale of the port city (reflected 
by GDP), $P R_{i j}$ is the ratio of the port cargo throughput to the total port cargo throughput of the measured time interval, $C R_{i j}$ is the ratio of the city economy scale to the total economy scale of the measured time interval, $R C I_{i j}$ represents the RCI of the port city i. According to this formula, the larger the value of $P R_{i p}$ the stronger the intermediary of the port city in year $\mathrm{j}$; the larger the $C R_{i p}$ the stronger the concentration of the city's economy. If $R C I_{i j}$ is greater than 1, it indicates that the intermediary is higher than the concentration, which means the development of the port is faster than the urban economy development; if $R C I_{i j}$ is less than 1, it means that the intermediary is lower than the concentration, which means the port development is slower than the urban economy development; if $R C I_{i j}$ is the close to 1 , it indicates that the development of urban economy and the development of port are coordinating. Based on the data from 2005 to 2014, the RCI index of the major port cities in the Yangtze River Delta and Pearl River Delta are shown in Table 1. Figure 2 and Figure 3 are the graphs of

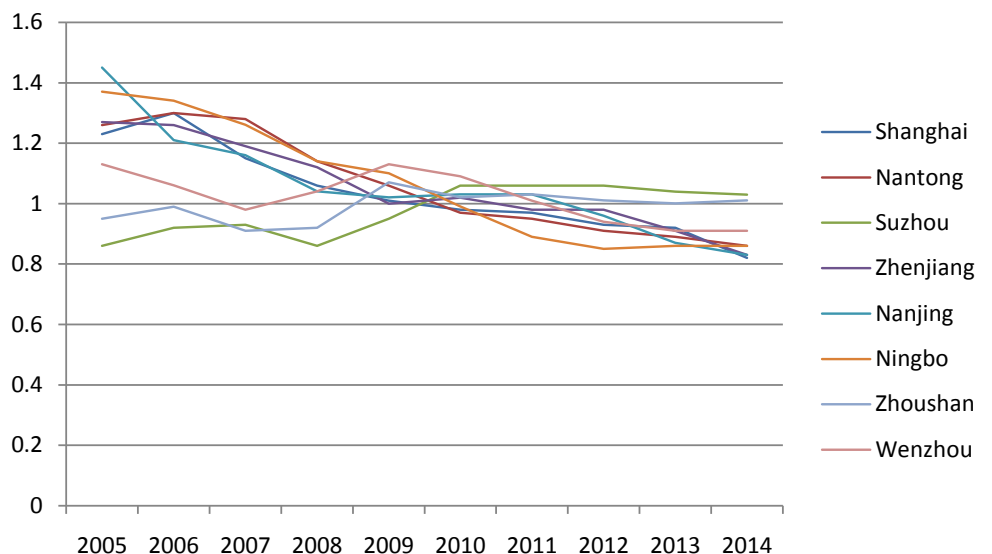

Figure 3. RCI of major ports in the Yangtze River Delta.

Table 1. RCI of major port cities in Yangtze River Delta and the Pearl River Delta.

\begin{tabular}{ccccccccccc}
\hline RCI & 2005 & 2006 & 2007 & 2008 & 2009 & 2010 & 2011 & 2012 & 2013 & 2014 \\
\hline Guangzhou & 1.38 & 1.41 & 1.35 & 1.16 & 1.07 & 1.03 & 0.94 & 0.87 & 0.80 & 0.78 \\
Shenzhen & 1.48 & 1.44 & 1.40 & 1.29 & 1.11 & 1.08 & 0.93 & 0.84 & 0.77 & 0.67 \\
Zhuhai & 1.10 & 0.94 & 0.82 & 0.81 & 0.83 & 0.98 & 1.00 & 1.01 & 1.17 & 1.13 \\
Dongguan & 0.73 & 0.52 & 0.44 & 0.60 & 0.65 & 0.92 & 1.00 & 1.28 & 1.41 & 1.53 \\
Huizhou & 0.78 & 0.93 & 0.87 & 0.83 & 1.12 & 1.13 & 1.03 & 0.92 & 1.24 & 0.90 \\
Shanghai & 1.23 & 1.30 & 1.15 & 1.06 & 1.01 & 0.98 & 0.97 & 0.93 & 0.92 & 0.82 \\
Nantong & 1.26 & 1.30 & 1.28 & 1.14 & 1.06 & 0.97 & 0.95 & 0.91 & 0.89 & 0.86 \\
Suzhou & 0.86 & 0.92 & 0.93 & 0.86 & 0.95 & 1.06 & 1.06 & 1.06 & 1.04 & 1.03 \\
Zhenjiang & 1.27 & 1.26 & 1.19 & 1.12 & 1.00 & 1.02 & 0.98 & 0.98 & 0.91 & 0.83 \\
Nanjing & 1.45 & 1.21 & 1.16 & 1.04 & 1.02 & 1.03 & 1.03 & 0.96 & 0.87 & 0.83 \\
Ningbo & 1.37 & 1.34 & 1.26 & 1.14 & 1.10 & 0.99 & 0.89 & 0.85 & 0.86 & 0.86 \\
Zhoushan & 0.95 & 0.99 & 0.91 & 0.92 & 1.07 & 1.02 & 1.03 & 1.01 & 1.00 & 1.01 \\
Wenzhou & 1.13 & 1.06 & 0.98 & 1.04 & 1.13 & 1.09 & 1.01 & 0.94 & 0.91 & 0.91 \\
\hline
\end{tabular}


RCI of major port cities in the Yangtze River Delta and the Pearl River Delta respectively.

On the whole, the RCI of the major port cities of the Yangtze River Delta in the past 10 years trends to 1 , which indicates that the port-city relationship of these port cities trend to be coordinated, while the RCI of the major port cities of the Pearl River Delta has been fluctuating around 1 in recent years, which means port-city relationship of the major port cities in Pearl River Delta is still in a state of uncoordinated, but we can see a slight trend of approaching 1 in Figure 4.

\section{Gray Relational Analysis}

Gray relational analysis is based on the microscopic or macroscopic geometric approximation of the sequence of behavioral factors to analyze and determine the degree of influence between factors or the factors that measure the contribution of the main behavior. Gray relational analysis is mainly on the development of changes in the situation analysis, that is, the dynamic development of the system quantitative analysis. The basic idea is to determine the relationship between the similarity of the sequence curve geometry, the closer the curve, the greater the correlation between the corresponding sequence, and vice versa. The gray relational analysis method makes up for the shortcomings caused by the system analysis of the mathematical statistics method. It does not have the requirement of the sample quantity and the regularity of the sample, and it is very easy to calculate.

Port system and urban economy system are gray systems. First, because the factors that reflect port development and urban economy development are too many and too complex, only limited indicators can be selected for analysis. Second, the statistics of the various indicators are very limited, and the existing data mostly are gray, most of the data is not a typical probability distribution. Thus, the analysis system has the characteristics of incomplete or "gray" information. This paper uses the gray relational analysis method to calculate the specific correlation between urban economy development and port development.

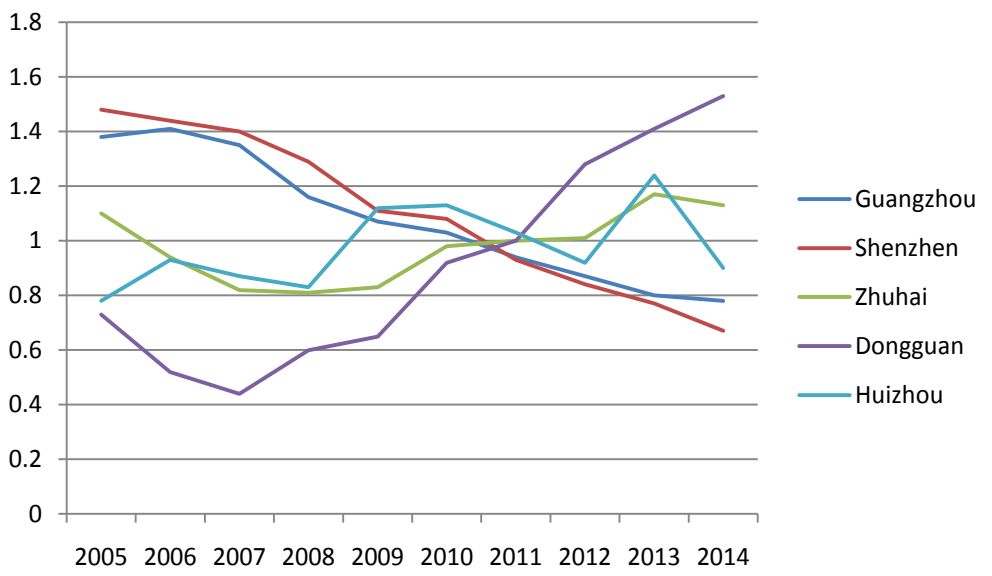

Figure 4. RCI of major ports in the Pearl River Delta. 


\subsection{Calculation of Gray Correlation Degree}

Let $X_{k}$ be the system factor, and its observation data on the serial number is $x_{k i}$ $(i=1, \cdots, n)$, then $X_{k}\left(=x_{k 1}, x_{k 2}, \cdots, x_{k n}\right)$ is the behavior sequence of factor $X_{k}$, which is the index number, $x_{k i}$ for the factor $X_{k}$ on the first $k$ indicators of the observed data,

$\left(x_{i 1}-x_{i 1}, x_{i 2}-x_{i 1}, \cdots, x_{i n}-x_{i 1}\right)$ is $X_{i}-x_{i 1}$, let $s_{i}=\int_{1}^{n}\left(X_{i}-x_{i 1}\right) \mathrm{d} t$, then

(i) When $X_{i}$ is an ascending sequence, $s_{i} \geq 0$;

(ii) when $X_{i}$ is the descending column, $s_{i} \leq 0$;

(iii) When $X_{i}$ is the oscillation sequence, the $s_{i}$ symbol is indefinite.

If the length of sequence $X_{k}$ and the sequence $X_{m}$ are the same, then $\varepsilon_{k m}=\frac{1+\left|s_{k}\right|+\left|s_{m}\right|}{1+\left|s_{k}\right|+\left|s_{m}\right|+\left|s_{k}-s_{m}\right|}$ is the gray absolute correlation degree of $X_{k}$ and $X_{m}$.

Let the sequence $X_{k}, X_{m}$ the same length, and the initial value is not equal to zero, then make

$$
X_{k}^{\prime}=\left(\frac{x_{k 1}}{x_{k 1}}, \frac{x_{k 2}}{x_{k 1}}, \cdots, \frac{x_{k n}}{x_{k 1}}\right) \quad X_{m}^{\prime}=\left(\frac{x_{m 1}}{x_{m 1}}, \frac{x_{m 2}}{x_{m 1}}, \cdots, \frac{x_{m n}}{x_{m 1}}\right)
$$

$X_{k}^{\prime}$ and $X_{m}^{\prime}$ are the values transformed by initialization. The gray correlation between $X_{k}^{\prime}$ and $X_{m}^{\prime}$ is the gray relative correlation degree of $X_{k}$ and $X_{m}$, denoted as $r_{\mathrm{km}}$.

Let $X_{k}$ and $X_{m}$ have the same length and the initial value is different from zero, which means $X_{k 1}$ and $X_{m 1}$ are not zero, $\varepsilon_{k m}$ and $r_{k m}$ are gray absolute correlation degree and gray relative correlation degree of $X_{k}$ and $X_{m}$ respectively, and the resolution coefficient $\theta \in[0,1]$, then

$$
\rho_{\mathrm{k} m}=\theta \varepsilon_{k m}+(1-\theta) r_{k m}
$$

$\rho_{k m}$ is the gray comprehensive correlation degree of $X_{k}$ and $X_{m}$. The gray comprehensive correlation degree not only reflects the similarity degree of the two sequences in the graph, but also reflects the degree of closeness of the two sequences relative to the starting point. It is a comprehensive indicator of whether the links are closely related. In general, the resolution coefficient is $\theta=$ 0.5 , and if we are more concerned with the difference between the absolute quantities of the two sequences, $\theta$ can be larger; if we pay more attention to the difference in the rate of change between the two sequences relative to the starting point, $\theta$ can be made smaller.

In the gray correlation calculation of this paper, the original data is first transformed by initialization, and then the comprehensive gray correlation degree between the parent sequence and the subsequence is calculated, and the resolution coefficient $\theta=0.5$ is set.

\subsection{The Selection of Indicators}

Port system and urban economy system are complex systems and lots of indicators can reflect the situation of them. The focus of this paper is to study the inte- 
raction between urban economy development and port development. Therefore, the port cargo throughput $\left(\mathrm{Y}_{1}\right)$, which is the most representative indicator of port system, is chosen to represent the port system. The urban economy system is more complex. GDP $\left(\mathrm{X}_{1}\right)$, fixed assets investment $\left(\mathrm{X}_{2}\right)$, import and export value $\left(\mathrm{X}_{3}\right)$, industrial output $\left(\mathrm{X}_{4}\right)$, freight volume $\left(\mathrm{X}_{5}\right)$ and premium income $\left(\mathrm{X}_{6}\right)$ are chosen to reflect the degree of development of the urban economy. GDP is obviously the most representative indicator of urban economy. Fixed assets investment mainly includes capital construction, renovation, real estate development and other economic activities, in which process the port plays an important role. Import and export value can reflect the degree of demand of a city to the port. The quality of raw materials and finished products used in the industrial production process are mostly transported by ship, and gross industrial output is the best indicator of industrial development. Port is an important infrastructure for urban transport, freight volume $\left(\mathrm{X}_{5}\right)$ can directly reflect city's demand for the port. The financial industry is at the core of the modern economy and the insurance industry is an important branch of the financial industry, the change of the premium income $\left(\mathrm{X}_{6}\right)$ can indirectly reflect the development of the financial industry.

\subsection{Calculation Results}

Major cities of the Yangtze River Delta and the Pearl River Delta are selected for empirical analysis, Shanghai, Nantong, Suzhou, Zhenjiang, Nanjing, Ningbo, Zhoushan and Wenzhou are selected for the Yangtze River Delta; Guangzhou, Shenzhen, Zhuhai, Huizhou and Dongguan are selected for the Pearl River Delta. The port cargo throughput $\left(\mathrm{Y}_{1}\right)$ is set to be the parent sequence, GDP $\left(\mathrm{X}_{1}\right)$, fixed asset investment $\left(\mathrm{X}_{2}\right)$, import and export value $\left(\mathrm{X}_{3}\right)$, industrial output $\left(\mathrm{X}_{4}\right)$, freight volume $\left(\mathrm{X}_{5}\right)$ and premium income $\left(\mathrm{X}_{6}\right)$ are sub-sequences, then we can obtain the gray correlation coefficients of the two sequences. The correlation coefficients of parent sequence and sub-sequences are shown in Table 2.

In Table 2, it can be seen that in the urban economy system, the average gray correlation coefficient of GDP $\left(\mathrm{X}_{1}\right)$ and port cargo throughput $\left(\mathrm{Y}_{1}\right)$ is 0.750 , and the average gray correlation coefficient of industrial output $\left(\mathrm{X}_{4}\right)$ and port cargo throughput $\left(\mathrm{Y}_{1}\right)$ is 0.764 , while the other average gray correlation coefficients are small, all around 0.70 . This shows that the port city's GDP is highly related to its port development, so port development should be referred to port city's GDP growth. The correlation coefficient between port cargo throughput $\left(\mathrm{Y}_{1}\right)$ and industrial output $\left(\mathrm{X}_{4}\right)$ is 0.764 , which is the largest correlation coefficient between port index and urban economy index correlation coefficient. This is mainly because the industrial production needs to use coal, oil, steel and other raw materials which are big and heavy, and water transport is the best mode of transport; Second, the industrial production is mostly large quality and volume of products, water transport costs less. Therefore, in the process the port city's development of industry, we should pay more attention to the construction of port facilities. 
Table 2. Gray correlation coefficients of the two port groups.

\begin{tabular}{cccccccc}
\hline & $\mathrm{X}_{1}$ & $\mathrm{X}_{2}$ & $\mathrm{X}_{3}$ & $\mathrm{X}_{4}$ & $\mathrm{X}_{5}$ & $\mathrm{X}_{6}$ & Average value \\
\hline Guangzhou & 0.617 & 0.634 & 0.742 & 0.716 & 0.672 & 0.630 & 0.668 \\
Shenzhen & 0.678 & 0.790 & 0.673 & 0.752 & 0.649 & 0.611 & 0.692 \\
Zhuhai & 0.781 & 0.744 & 0.609 & 0.697 & 0.710 & 0.677 & 0.703 \\
Dongguan & 0.629 & 0.610 & 0.601 & 0.616 & 0.612 & 0.749 & 0.636 \\
Huizhou & 0.733 & 0.720 & 0.644 & 0.785 & 0.715 & 0.767 & 0.727 \\
Shanghai & 0.685 & 0.703 & 0.641 & 0.822 & 0.757 & 0.645 & 0.709 \\
Nantong & 0.689 & 0.682 & 0.719 & 0.603 & 0.640 & 0.619 & 0.659 \\
Suzhou & 0.861 & 0.866 & 0.682 & 0.819 & 0.606 & 0.956 & 0.798 \\
Zhenjiang & 0.828 & 0.648 & 0.870 & 0.665 & 0.737 & 0.765 & 0.752 \\
Nanjing & 0.704 & 0.636 & 0.718 & 0.821 & 0.730 & 0.663 & 0.712 \\
Ningbo & 0.687 & 0.640 & 0.685 & 0.734 & 0.941 & 0.565 & 0.709 \\
Zhoushan & 0.920 & 0.746 & 0.614 & 0.929 & 0.855 & 0.701 & 0.794 \\
Wenzhou & 0.939 & 0.598 & 0.920 & 0.977 & 0.605 & 0.797 & 0.806 \\
Average value & 0.750 & 0.694 & 0.701 & 0.764 & 0.710 & 0.703 & 0.720 \\
\hline
\end{tabular}

Source: Yearbook of Each City.

In order to analyze the differences of gray correlation coefficients between the Yangtze River Delta and the Pearl River Delta, the gray correlation coefficients of the two port groups are shown in Table 3 and Table 4 respectively.

It can be seen from Table 3, in the Yangtze River Delta, the average correlation coefficient between GDP $\left(\mathrm{X}_{1}\right)$ and cargo port throughput $\left(\mathrm{Y}_{1}\right)$ is 0.789 , the average correlation coefficient between industrial output $\left(\mathrm{X}_{4}\right)$ and port cargo throughput $\left(\mathrm{Y}_{1}\right)$ is 0.796 , both of them are still high compared to other correlation coefficients, and the average port-city correlation coefficient is 0.742 . In the Pearl River Delta, it can be seen in Table 4, only the average correlation coefficient of industrial output $\left(\mathrm{X}_{4}\right)$ and port cargo throughput $\left(\mathrm{Y}_{1}\right)$ exceeded 0.7, up to 0.713 , the remaining correlation coefficient are below 0.7 , the average port-city correlation coefficient is 0.685 . Compared with the gray correlation coefficient between the Yangtze River Delta and the Pearl River Delta, it can be seen that the port-city correlation of the Yangtze River Delta is relatively high, while the port-city relationship of the Pearl River Delta is lower, indicating that compared with the Pearl River Delta, the port-city relationship of the Yangtze River Delta is more coordinated.

\section{Impulse Response Analysis}

In this section, the vector autoregressive (VAR) model is used to determine the extent of the impact of port development on port cities. Vector autoregressive (VAR) is a model based on statistical properties of data that can be used to correlate time series data [5]. It is predicted that this method has been widely used in unstructured models in macroeconomic analysis in recent years. We have already found that GDP and industrial output have high correlation to the port 
Table 3. Gray correlation coefficients of the Yangtze River Delta.

\begin{tabular}{cccccccc}
\hline & $\mathrm{X}_{1}$ & $\mathrm{X}_{2}$ & $\mathrm{X}_{3}$ & $\mathrm{X}_{4}$ & $\mathrm{X}_{5}$ & $\mathrm{X}_{6}$ & Average value \\
\hline Shanghai & 0.685 & 0.703 & 0.641 & 0.822 & 0.757 & 0.645 & 0.709 \\
Nantong & 0.689 & 0.682 & 0.719 & 0.603 & 0.640 & 0.619 & 0.659 \\
Suzhou & 0.861 & 0.866 & 0.682 & 0.819 & 0.606 & 0.956 & 0.798 \\
Zhenjiang & 0.828 & 0.648 & 0.870 & 0.665 & 0.737 & 0.765 & 0.752 \\
Nanjing & 0.704 & 0.636 & 0.718 & 0.821 & 0.730 & 0.663 & 0.712 \\
Ningbo & 0.687 & 0.640 & 0.685 & 0.734 & 0.941 & 0.565 & 0.709 \\
Zhoushan & 0.920 & 0.746 & 0.614 & 0.929 & 0.855 & 0.701 & 0.794 \\
Wenzhou & 0.939 & 0.598 & 0.920 & 0.977 & 0.605 & 0.797 & 0.806 \\
Average value & 0.789 & 0.690 & 0.731 & 0.796 & 0.734 & 0.714 & 0.742 \\
\hline
\end{tabular}

Source: Yearbook of Each City.

Table 4. Gray correlation coefficients of the Pearl River Delta.

\begin{tabular}{cccccccc}
\hline & $\mathrm{X}_{1}$ & $\mathrm{X}_{2}$ & $\mathrm{X}_{3}$ & $\mathrm{X}_{4}$ & $\mathrm{X}_{5}$ & $\mathrm{X}_{6}$ & Average value \\
\hline Guangzhou & 0.617 & 0.634 & 0.742 & 0.716 & 0.672 & 0.630 & 0.668 \\
Shenzhen & 0.678 & 0.790 & 0.673 & 0.752 & 0.649 & 0.611 & 0.692 \\
Zhuhai & 0.781 & 0.744 & 0.609 & 0.697 & 0.710 & 0.677 & 0.703 \\
Dongguan & 0.629 & 0.610 & 0.601 & 0.616 & 0.612 & 0.749 & 0.636 \\
Huizhou & 0.733 & 0.720 & 0.644 & 0.785 & 0.715 & 0.767 & 0.727 \\
Shanghai & 0.685 & 0.703 & 0.641 & 0.822 & 0.757 & 0.645 & 0.709 \\
Average value & 0.688 & 0.699 & 0.654 & 0.713 & 0.671 & 0.687 & 0.685 \\
\hline
\end{tabular}

Source: Yearbook of Each City.

cargo throughput both in the Yangtze River Delta and the Pearl River Delta, according to the measurement of the gray relational analysis. Therefore, in this section, we choose GDP and industrial output to represent the development of urban economy, which were recorded as GDP and I, the port development level is still measured by the port cargo throughput, recorded as T. The impulse response analysis of these three indexes is carried out, and the dynamic characteristics of the port-city relationship are obtained.

\subsection{Vector Autoregressive (VAR) Model}

In order to compare the impulse response analysis of the Pearl River Delta and the Yangtze River Delta, the GDP, industrial output and port cargo throughput of major port cities in the Yangtze River Delta and Pearl River Delta ports were summarized. The data ranges from 1998 to 2014 . And then the analysis is shown in Table 5.

In order to eliminate the existence of collinearity and autocorrelation between indicators, the indicators are changed by natural logarithmic processing; the new sequences are recorded as $\operatorname{lnGDP}, \ln I$ and $\ln \mathrm{T}$, and the timing diagram of them are shown in Figure 5 and Figure 6, respectively. It is easy to see, whether in the 
Table 5. Data of the Yangtze River Delta and Pearl River Delta.

\begin{tabular}{|c|c|c|c|c|c|c|}
\hline \multirow[b]{2}{*}{ Year } & \multicolumn{3}{|c|}{ The Yangtze River Delta } & \multicolumn{3}{|c|}{ The Pearl River Delta } \\
\hline & $\begin{array}{c}\text { GDP } \\
(100 \text { million Yuan })\end{array}$ & $\begin{array}{c}\text { I } \\
(100 \text { million Yuan })\end{array}$ & $\begin{array}{c}\mathrm{T} \\
\text { (10 thousand tons) }\end{array}$ & $\begin{array}{c}\text { GDP } \\
(100 \text { million Yuan })\end{array}$ & $\begin{array}{c}\text { I } \\
(100 \text { million Yuan })\end{array}$ & $\begin{array}{c}\mathrm{T} \\
\text { (10 thousand tons) }\end{array}$ \\
\hline 1998 & 8608 & 13294 & 42027 & 4605 & 5948 & 14548 \\
\hline 1999 & 9387 & 14655 & 49868 & 5288 & 6671 & 18761 \\
\hline 2000 & 10619 & 17078 & 56915 & 6270 & 7959 & 21493 \\
\hline 2001 & 11783 & 18928 & 60353 & 7163 & 9100 & 23897 \\
\hline 2002 & 13246 & 21946 & 70559 & 8297 & 10793 & 30446 \\
\hline 2003 & 15903 & 28475 & 86412 & 9861 & 14395 & 36340 \\
\hline 2004 & 19227 & 35524 & 107208 & 11777 & 17847 & 44769 \\
\hline 2005 & 22524 & 45697 & 125568 & 13728 & 21162 & 49986 \\
\hline 2006 & 26122 & 55518 & 237048 & 16199 & 25622 & 58008 \\
\hline 2007 & 31090 & 68027 & 163725 & 19115 & 30559 & 65100 \\
\hline 2008 & 35911 & 78033 & 175203 & 22079 & 34721 & 67957 \\
\hline 2009 & 38953 & 54878 & 188964 & 23668 & 35411 & 68662 \\
\hline 2010 & 45724 & 67644 & 215380 & 27741 & 42377 & 80973 \\
\hline 2011 & 52707 & 78719 & 242463 & 32217 & 48505 & 86282 \\
\hline 2012 & 57711 & 83163 & 256126 & 35451 & 50457 & 90155 \\
\hline 2013 & 62946 & 89248 & 274379 & 39894 & 55019 & 99921 \\
\hline 2014 & 67983 & 93933 & 284286 & 43458 & 58668 & 102510 \\
\hline
\end{tabular}

Source: Yearbook of Each City.

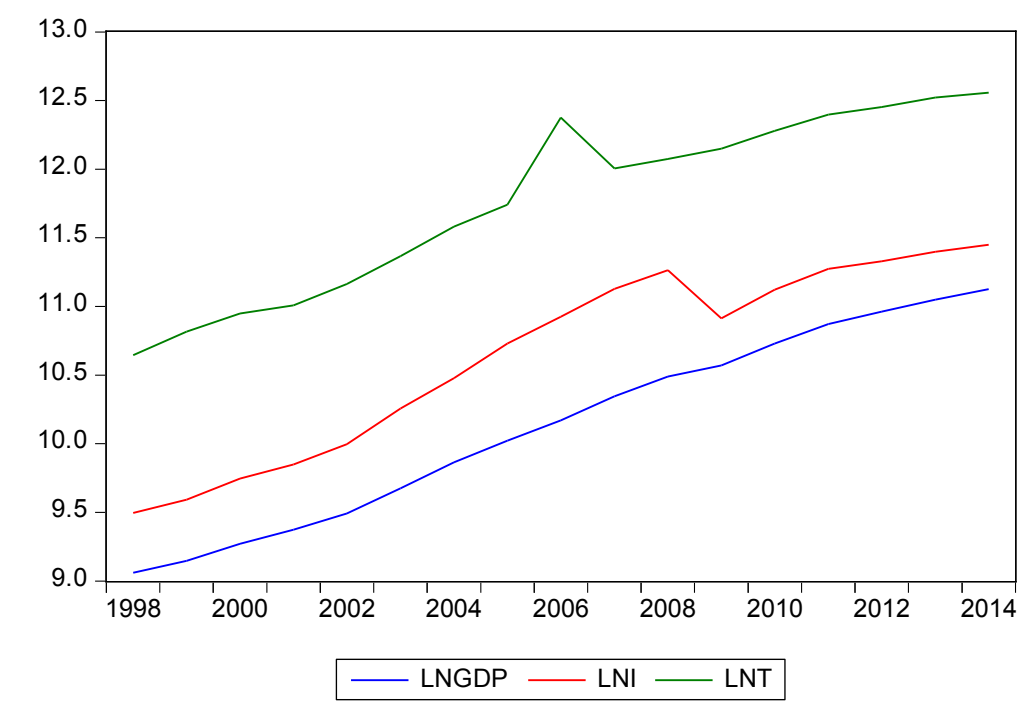

Figure 5. Timing diagram of the Yangtze River Delta.

Yangtze River Delta or the Pearl River Delta, sequences have generally consistent trends.

The maximum hysteresis order is required before vector autoregressive of the sequence. Table 6 and Table 7 are the results of the hysteresis order of the 


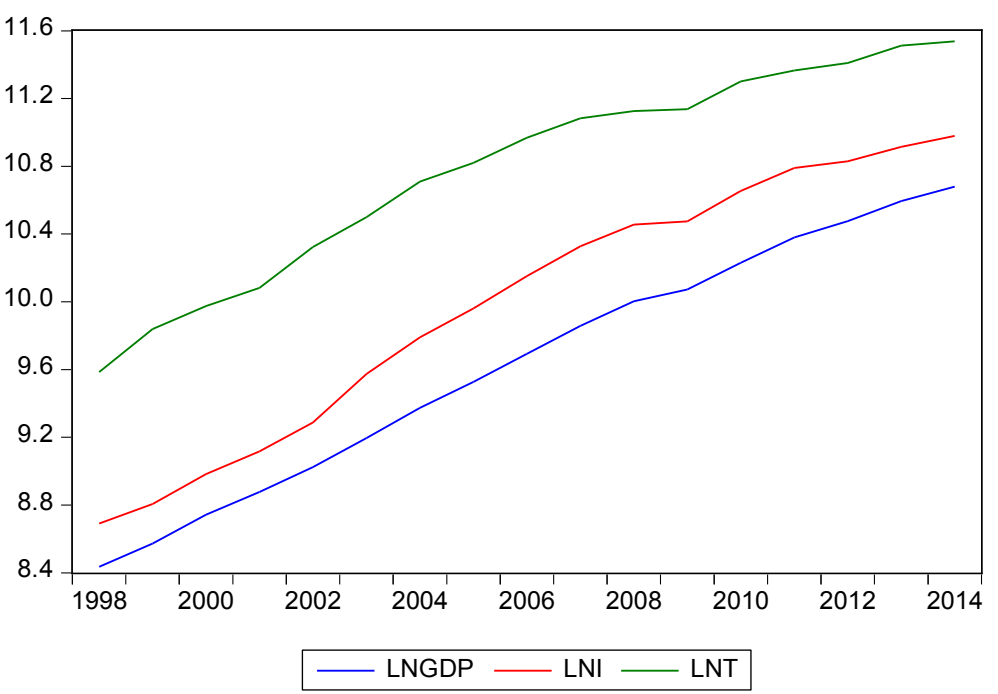

Figure 6. Timing diagram of the Pearl River Delta.

Table 6. Hysteresis results of the Yangtze River Delta.

\begin{tabular}{ccccccc}
\hline Lag & LogL & LR & FPE & AIC & SC & HQ \\
\hline 0 & 3.547845 & NA & 0.000186 & -0.078264 & 0.058677 & -0.090940 \\
1 & 55.03418 & $73.55190^{*}$ & $4.51 \mathrm{e}-07$ & -6.147739 & -5.599976 & -6.198445 \\
2 & 68.99631 & 13.96214 & $2.84 \mathrm{e}-07$ & -6.856616 & -5.898030 & -6.945351 \\
3 & 98.45278 & 16.83227 & $3.38 \mathrm{e}-08^{*}$ & $-9.778968^{*}$ & $-8.409560^{*}$ & $-9.905732^{\star}$ \\
\hline
\end{tabular}

Table 7. Hysteresis results of the Pearl River Delta.

\begin{tabular}{ccccccc}
\hline Lag & LogL & LR & FPE & AIC & SC & HQ \\
\hline 0 & 33.62678 & NA, & $2.53 \mathrm{e}-06$ & -4.375254 & -4.238314 & -4.387931 \\
1 & 101.7690 & 97.34604 & $5.68 \mathrm{e}-10$ & -12.82414 & -12.27638 & -12.87485 \\
2 & 119.2086 & $17.43959^{*}$ & $2.18 \mathrm{e}-10$ & -14.02980 & -13.07121 & -14.11853 \\
3 & 137.5347 & 10.47209 & $1.27 \mathrm{e}-10^{\star}$ & $-15.36211^{\star}$ & $-13.99270^{*}$ & $-15.48887^{*}$ \\
\hline
\end{tabular}

Yangtze River Delta and the Pearl River Delta respectively, which are obtained by Eviews 8.0.

According to the information criterion, the values of AIC, SC and HQ are the smallest in the lagged phase 3, so both the maximum hysteresis order of the Yangtze River Delta and the Pearl River Delta are 3. Then we can obtain the results of the VAR parameter estimation, which are shown in Table 8 and Table 9 respectively, the table consists of three parts: the parameter estimation results of the model, the estimated standard deviation of the coefficients (in the parenthesis below the coefficient estimates), and the t-test statistic values (in the square brackets below the coefficient estimates).

From Table 7 and Table 8, the vector autoregressive equations of the Yangtze River Delta and the Pearl River Delta can be obtained respectively. The parameters are in matrix form. The specific equations are as follows: 
Table 8. Estimates of VAR model parameters for the Yangtze River Delta.

\begin{tabular}{|c|c|c|c|}
\hline & LNGDP & LNI & LNT \\
\hline \multirow[t]{3}{*}{$\operatorname{LNGDP}(-1)$} & 1.448412 & 0.232997 & -3.735995 \\
\hline & $(0.66896)$ & (1.68009) & $(1.71782)$ \\
\hline & [2.16517] & {$[0.13868]$} & {$[-2.17485]$} \\
\hline \multirow[t]{3}{*}{$\operatorname{LNGDP}(-2)$} & -0.765668 & 0.388199 & 7.027951 \\
\hline & $(1.02920)$ & $(2.58484)$ & $(2.64287)$ \\
\hline & {$[-0.74394]$} & {$[0.15018]$} & [2.65921] \\
\hline \multirow[t]{3}{*}{$\operatorname{LNGDP}(-3)$} & 0.265389 & -0.186889 & -2.173504 \\
\hline & $(0.69600)$ & $(1.74802)$ & $(1.78726)$ \\
\hline & [ 0.38130$]$ & {$[-0.10692]$} & {$[-1.21611]$} \\
\hline \multirow[t]{3}{*}{ LNI(-1) } & 0.012649 & 0.997229 & 2.958860 \\
\hline & $(0.28489)$ & $(0.71549)$ & $(0.73155)$ \\
\hline & {$[0.04440]$} & [1.39377] & [4.04462] \\
\hline \multirow[t]{3}{*}{ LNI(-2) } & 0.172250 & 0.202490 & -0.193589 \\
\hline & $(0.20544)$ & $(0.51597)$ & $(0.52756)$ \\
\hline & {$[0.83843]$} & {$[0.39244]$} & {$[-0.36695]$} \\
\hline \multirow[t]{3}{*}{ LNI $(-3)$} & 0.082345 & 0.340394 & 1.172043 \\
\hline & $(0.13195)$ & $(0.33140)$ & $(0.33884)$ \\
\hline & {$[0.62404]$} & {$[1.02713]$} & [3.45894] \\
\hline \multirow[t]{3}{*}{$\mathrm{LNT}(-1)$} & 0.027433 & 0.092985 & -0.941460 \\
\hline & $(0.12489)$ & $(0.31366)$ & $(0.32070)$ \\
\hline & {$[0.21966]$} & {$[0.29645]$} & {$[-2.93560]$} \\
\hline \multirow[t]{3}{*}{ LNT(-2) } & -0.094159 & -0.105637 & -1.364083 \\
\hline & $(0.15726)$ & $(0.39497)$ & $(0.40384)$ \\
\hline & {$[-0.59873]$} & {$[-0.26746]$} & {$[-3.37781]$} \\
\hline \multirow[t]{3}{*}{ LNT(-3) } & -0.176624 & -1.079947 & -2.053766 \\
\hline & $(0.18287)$ & $(0.45928)$ & $(0.46959)$ \\
\hline & {$[-0.96584]$} & {$[-2.35139]$} & {$[-4.37351]$} \\
\hline \multirow[t]{3}{*}{$\mathrm{C}$} & 0.633445 & 2.679898 & 9.935453 \\
\hline & $(0.64779)$ & $(1.62692)$ & $(1.66345)$ \\
\hline & [0.97786] & [1.64722] & [5.97280] \\
\hline
\end{tabular}

The Yangtze River Delta:

$$
\begin{aligned}
L= & {\left[\begin{array}{ccc}
1.45 & 0.01 & 0.03 \\
0.23 & 1.00 & 0.09 \\
-3.74 & 2.96 & -0.94
\end{array}\right] * L_{t-1}+\left[\begin{array}{ccc}
-0.77 & 0.17 & -0.09 \\
0.39 & 0.20 & -0.11 \\
7.03 & -0.19 & -1.36
\end{array}\right] * L_{t-2} } \\
& +\left[\begin{array}{ccc}
0.27 & 0.08 & -0.17 \\
-0.19 & 0.34 & -1.07 \\
-2.17 & 1.17 & -2.05
\end{array}\right] * L_{t-3}+\left[\begin{array}{c}
0.63 \\
2.68 \\
9.94
\end{array}\right]
\end{aligned}
$$

The Pearl River Delta: 
Table 9. Estimates of VAR model parameters for the Pearl River Delta.

\begin{tabular}{|c|c|c|c|}
\hline & LNGDP & LNI & LNT \\
\hline \multirow{3}{*}{$\operatorname{LNGDP}(-1)$} & -1.476399 & -4.421308 & -3.927422 \\
\hline & $(1.01176)$ & $(1.07694)$ & $(1.70000)$ \\
\hline & {$[-1.45924]$} & {$[-4.10544]$} & {$[-2.31024]$} \\
\hline \multirow[t]{3}{*}{$\operatorname{LNGDP}(-2)$} & 2.843193 & 5.617380 & 5.219405 \\
\hline & (1.92608) & $(2.05015)$ & (3.23627) \\
\hline & {$[1.47616]$} & [2.73998] & [1.61278] \\
\hline \multirow[t]{3}{*}{$\operatorname{LNGDP}(-3)$} & -1.021080 & -2.133103 & -1.398470 \\
\hline & $(1.44292)$ & $(1.53587)$ & $(2.42446)$ \\
\hline & {$[-0.70765]$} & {$[-1.38885]$} & {$[-0.57682]$} \\
\hline \multirow[t]{3}{*}{ LNI(-1) } & 1.004061 & 2.221333 & 1.742518 \\
\hline & $(0.66945)$ & $(0.71257)$ & $(1.12484)$ \\
\hline & [1.49983] & [3.11733] & [1.54913] \\
\hline \multirow[t]{3}{*}{ LNI(-2) } & -0.494877 & -1.044228 & -1.529833 \\
\hline & $(0.60205)$ & $(0.64084)$ & (1.01159) \\
\hline & {$[-0.82198]$} & {$[-1.62947]$} & {$[-1.51230]$} \\
\hline \multirow[t]{3}{*}{$\mathrm{LNI}(-3)$} & 0.526880 & 1.064426 & 0.238066 \\
\hline & $(0.57283)$ & $(0.60973)$ & $(0.96249)$ \\
\hline & [0.91979] & [1.74574] & {$[0.24734]$} \\
\hline \multirow[t]{3}{*}{$\operatorname{LNT}(-1)$} & 0.648023 & 1.617039 & 1.151234 \\
\hline & $(0.37119)$ & $(0.39510)$ & $(0.62369)$ \\
\hline & [1.74580] & [4.09272] & [1.84585] \\
\hline \multirow[t]{3}{*}{ LNT(-2) } & -0.921883 & -1.692525 & -0.801260 \\
\hline & $(0.71905)$ & $(0.76537)$ & $(1.20817)$ \\
\hline & {$[-1.28209]$} & {$[-2.21139]$} & {$[-0.66320]$} \\
\hline \multirow[t]{3}{*}{ LNT(-3) } & -0.271492 & -0.417835 & 0.128999 \\
\hline & $(0.27920)$ & $(0.29719)$ & $(0.46912)$ \\
\hline & {$[-0.97239]$} & {$[-1.40597]$} & {$[0.27498]$} \\
\hline \multirow[t]{3}{*}{$\mathrm{C}$} & 1.993856 & 2.135474 & 2.391222 \\
\hline & $(1.71462)$ & $(1.82508)$ & $(2.88098)$ \\
\hline & [1.16285] & [1.17007] & {$[0.83000]$} \\
\hline
\end{tabular}

$$
\begin{aligned}
L= & {\left[\begin{array}{lll}
-1.47 & 1.00 & 0.65 \\
-4.42 & 2.22 & 1.62 \\
-3.93 & 1.74 & 1.15
\end{array}\right] * L_{t-1}+\left[\begin{array}{ccc}
2.84 & -0.49 & -0.92 \\
5.62 & -1.04 & -1.69 \\
5.22 & -1.53 & -0.80
\end{array}\right] * L_{t-2} } \\
& +\left[\begin{array}{ccc}
-1.02 & 0.53 & -0.27 \\
-2.13 & 1.06 & -0.42 \\
-1.40 & 0.24 & 0.13
\end{array}\right] * L_{t-3}+\left[\begin{array}{c}
1.99 \\
2.14 \\
2.39
\end{array}\right]
\end{aligned}
$$


where $L=$ [LNGDP LNI LNT]', $\mathrm{R}^{2}$ and the adjustment $\mathrm{R}^{2}$ of the regression equation are more than 0.99 , so the model of high degree of fit, indicating that the model is reasonable and stable.

The stationarity of the VAR model can be checked by the inverse roots of AR characteristic polynomial, in Figure 7, we can find that the reciprocal of the AR feature polynomial roots are all in the unit circle, which means the reciprocal absolute value of the eigenvalue is less than 1, indicating that the VAR satisfies the stationary condition.

Inverse Roots of AR Characteristic Polynomial

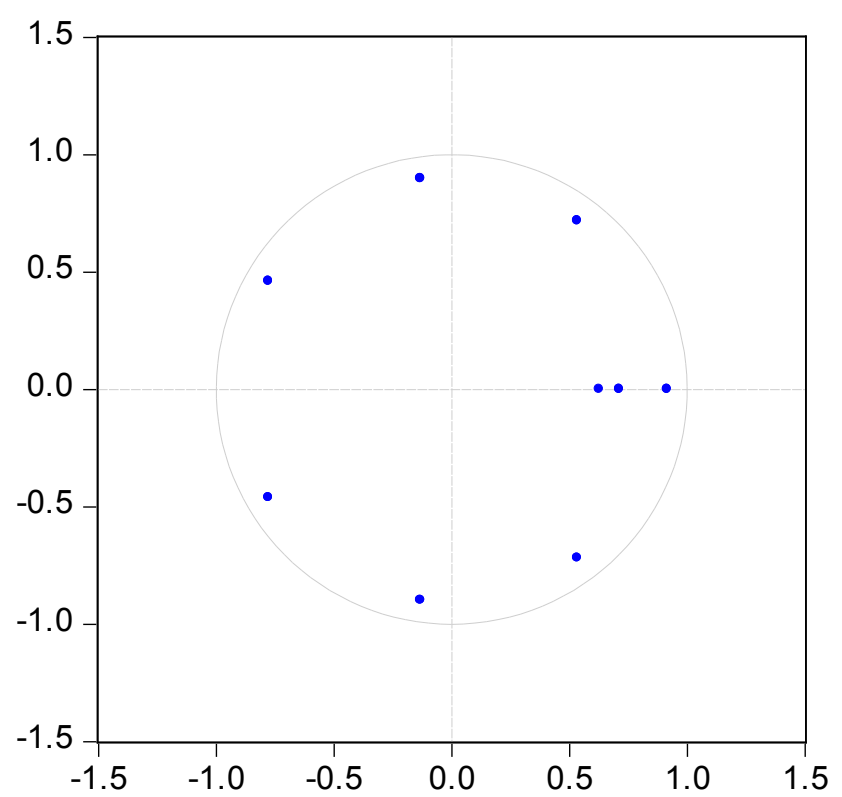

Inverse Roots of AR Characteristic Polynomial

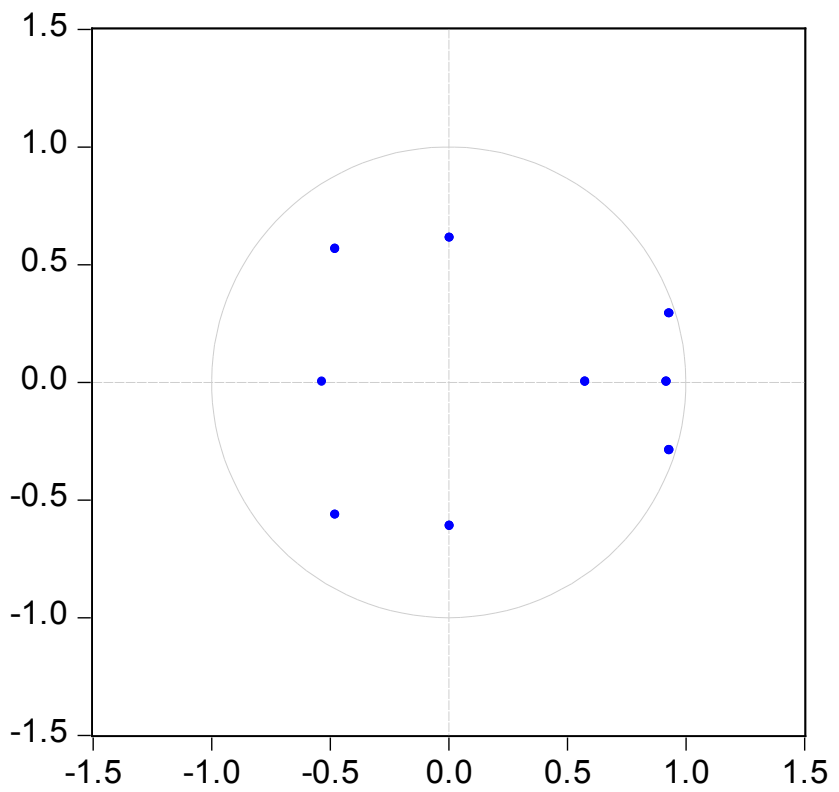

Figure 7. The inverse roots of AR characteristic polynomial. 


\subsection{Impulse Response Function}

The most important role of the VAR model is to reflect the dynamic characteristics of the system, that is because the change of each endogenous variable not only affects itself, but also affects all other endogenous variables by increasing the standard deviation of the error term in the impulse response function (IRF) . A change in the $\mathrm{i}$-th endogenous variable not only directly affects the $\mathrm{i}$-th variable, but also affects other endogenous variables through the dynamic structural features of the VAR model. The impulse response graph can visually reflect the trajectories of these effects; it can show how the variation of a variable affects all other variables through the model, and ultimately feedback to itself. In this paper, the $\operatorname{lnGDP}, \ln I$ and $\ln \mathrm{T}$ variables of the Yangtze River Delta and the Pearl River Delta are analyzed by Eviews 8.0 respectively. The impulse response graphs are shown in Figure 8 and Figure 9, respectively.

In the Yangtze River Delta, It can be seen from Figure 8(a) that the impact of the change of urban GDP on the port cargo throughput has shown a significant positive effect in the first four periods and has gradually increased, it begins to decline and gradually approaching zero from the fifth period. It can be seen from Figure 8(b), that the impact of the change of urban industrial output on the port cargo throughput in the Yangtze River Delta has shown a positive effect and gradually increased in the first two periods, and the effect begins to decrease from the third period and gradually approaches zero. From Figure 8(c) and Figure 8(d), it can be seen that the GDP and industrial output of port cities in the Yangtze River Delta have weaker positive impacts on the port cargo throughput in the short term, but then there is a negative effect, in the long term, the negative effect gradually approaches zero.

In the Pearl River Delta, it can be seen from Figure 9(a) that the impact of the change of urban GDP on the port cargo throughput is obvious in the first two periods, but the positive effect gradually decreases and approaches zero, then the positive effects are gradually strengthened and stabilized around zero. It can be seen from Figure 9(b) that the impact of the change of urban industrial output on the port cargo throughput has shown a significant increasing positive impact in the first two periods, but the positive impact begins to weaken and gradually approaches zero from the third period. As can be seen from Figure 9(c), the impact of the port cargo throughput change on port cities has shown an increasing positive impact on GDP in the first two periods, then the impact trends to be stabilized. It can be seen from Figure 9(d) that the impact of the change of urban industrial output on the port cargo throughput has shown a positive effect in the first two periods, and it tends to be stabilized from the third period.

Compared with impulse response maps of the Yangtze River Delta and the Pearl River Delta, it can be found that in both areas, the growth of GDP and industrial output can aggregate the development of port in the short term, and the impact approaches zero in the long term. However, the impacts of the development of the urban GDP and industrial output in the Yangtze River Delta are greater than that in the Pearl River Delta. At the same time, the development of 
Response of LNT to Cholesky

One S.D. LNGDP Innovation

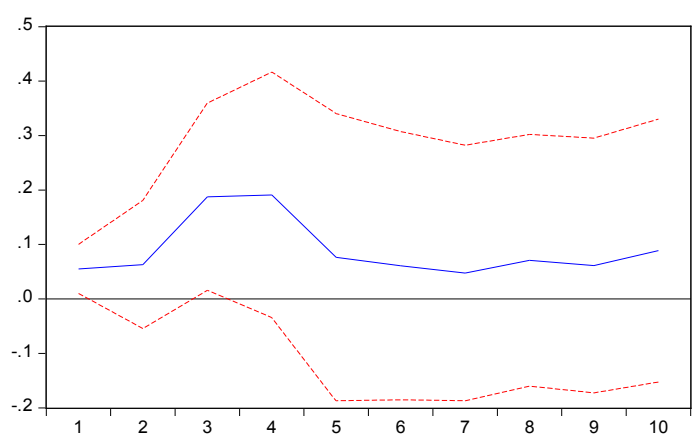

(a)

Response of LNT to Cholesky

One S.D. LNI Innovation

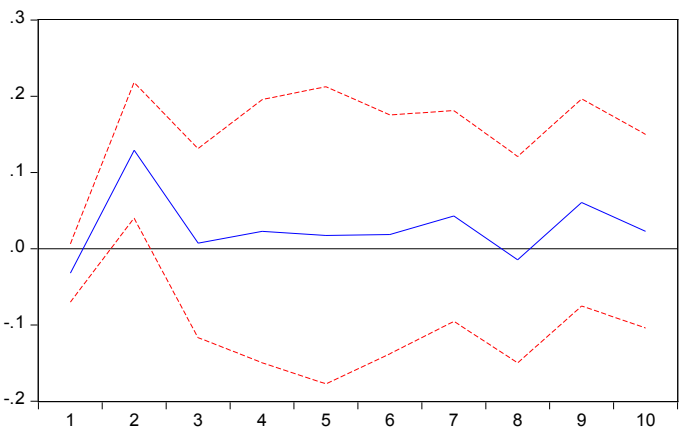

(b)

Response of LNGDP to Cholesky One S.D. LNT Innovation

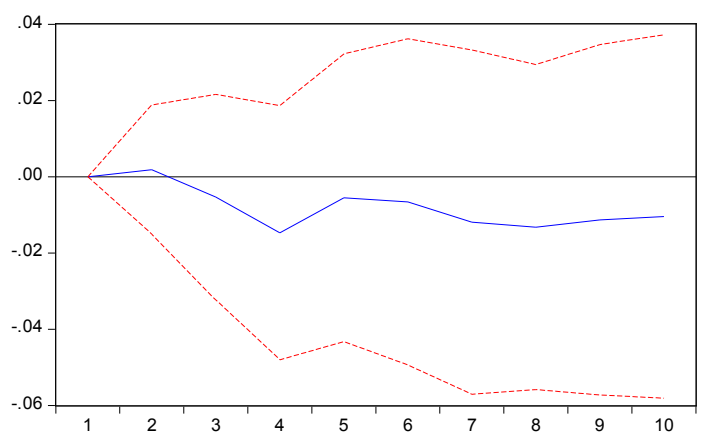

(c)

Response of LNI to Cholesky One S.D. LNT Innovation

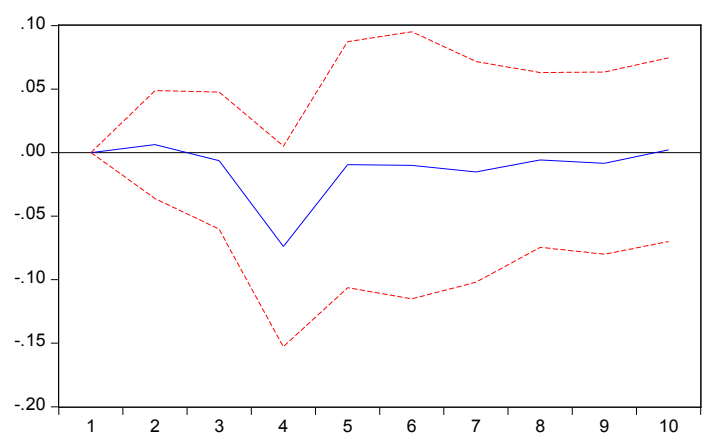

(d)

Figure 8. Impulse response graphs of the Yangtze River Delta. 
Response of LNT to Cholesky

One S.D. LNGDP Innovation

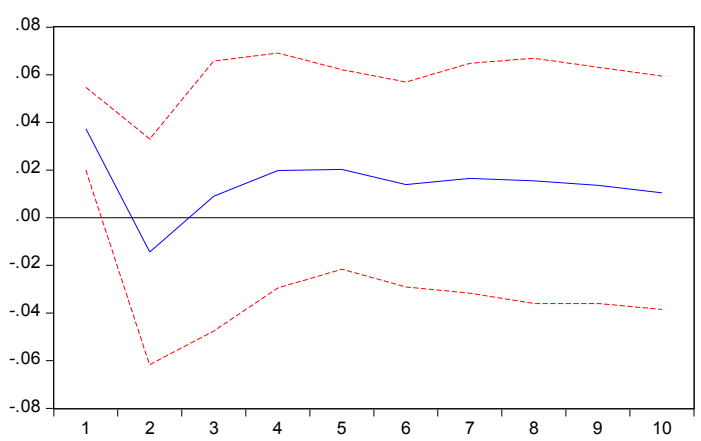

(a)

Response of LNT to Cholesky

One S.D. LNI Innovation

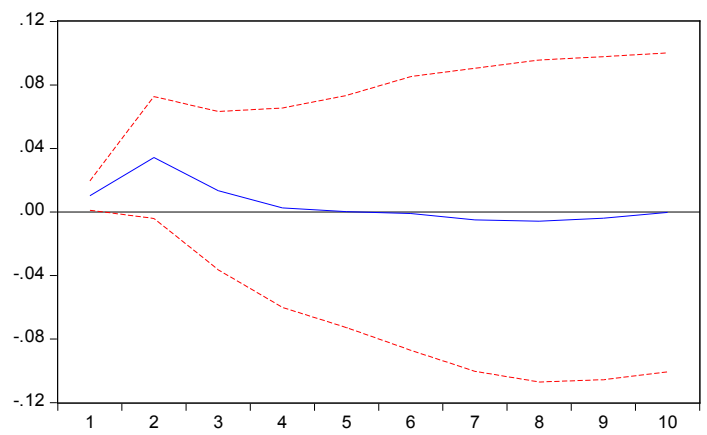

(b)

Response of LNGDP to Cholesky One S.D. LNT Innovation

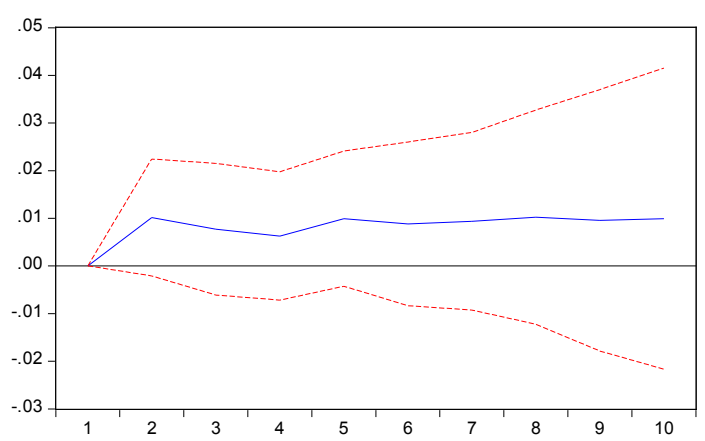

(c)

Response of LNI to Cholesky One S.D. LNT Innovation

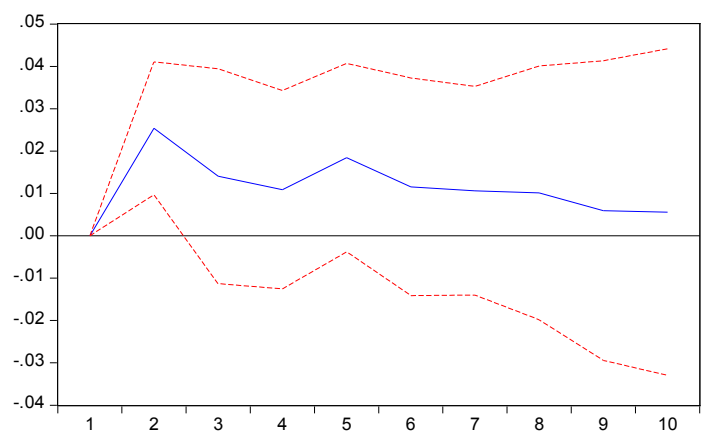

(d)

Figure 9. Impulse response graphs of the Pearl River Delta. 
port has little effect on the development of the urban GDP and industrial output in the Yangtze River Delta, but the development of port in the Pearl River Delta has a positive impact on the urban GDP and industrial output.

\subsection{Variance Decomposition}

The impulse response function reflects the dynamic influence of an endogenous variable on other endogenous variables. The variance decomposition divides the variance of a variable in the VAR model system into the perturbation terms [6]. The main idea is that the variation of each endogenous variable in the system is decomposed according to its origin, so that the degree of influence of other endogenous variables can be visually observed [7].

\subsubsection{The Impact of Urban Economy Development on Port Development}

The results of variance decomposition of LNT of the Yangtze River Delta and the Pearl River Delta are shown in Figure 10 and Figure 11 respectively.

From Figure 10, it can be seen that the contribution of GDP to port cargo throughput ( $\mathrm{T}$ ) in the Yangtze River Delta decreased from 35\% to $21 \%$ in the first two periods, but begins to rise sharply from the third period, and it finally stabilized around $75 \%$, while the contribution of industrial output(I) to port

Variance Decomposition

Percent LNT variance due to LNGDP

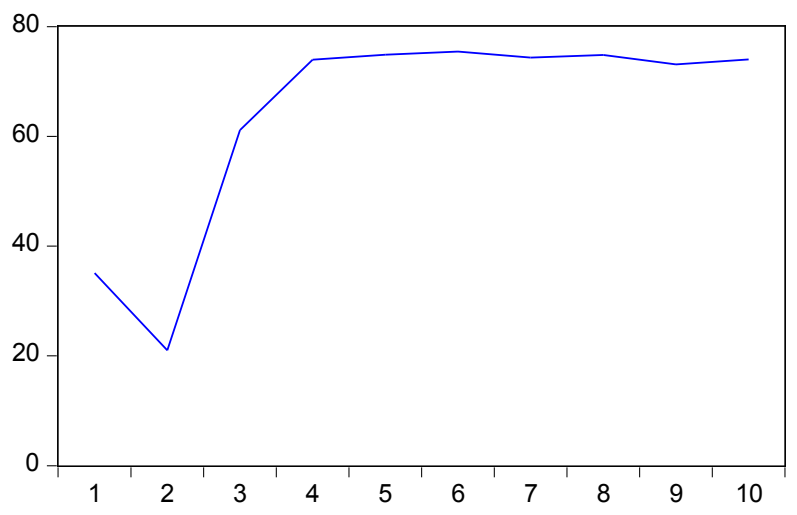

Percent LNT variance due to $\mathrm{LNI}$

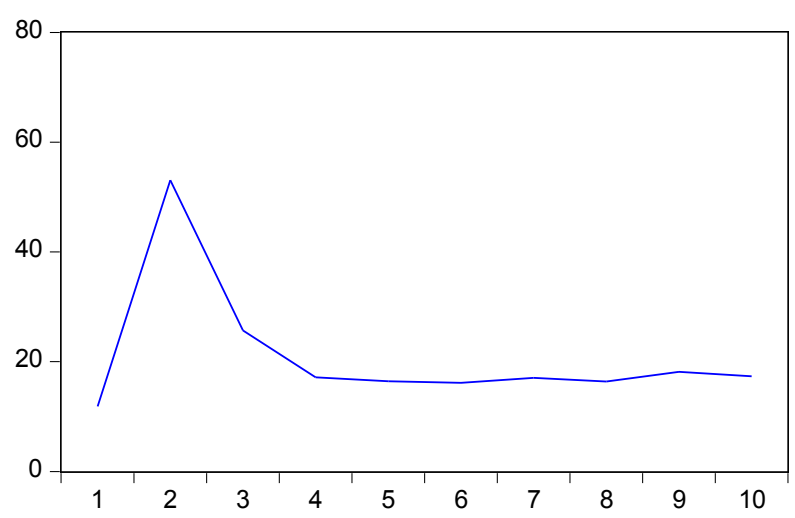

Figure 10. Variance decomposition of LNT of the Yangtze River Delta. 
Variance Decomposition

Percent LNT variance due to LNGDP

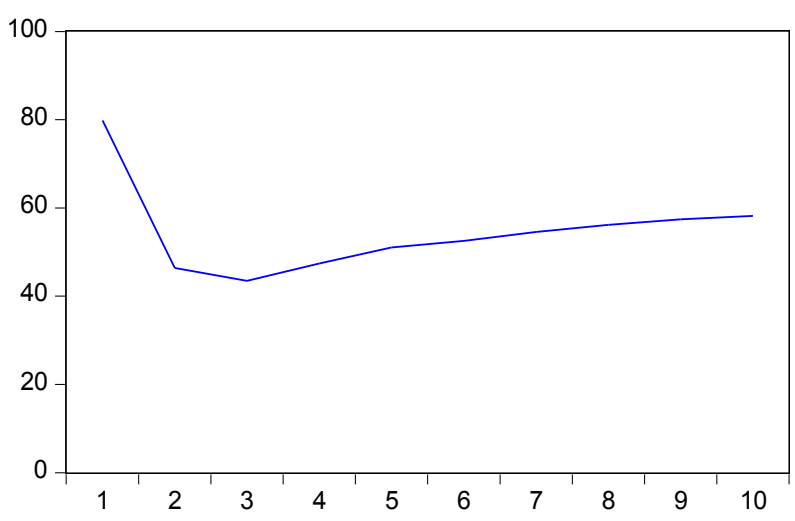

Percent LNT variance due to $\mathrm{LNI}$

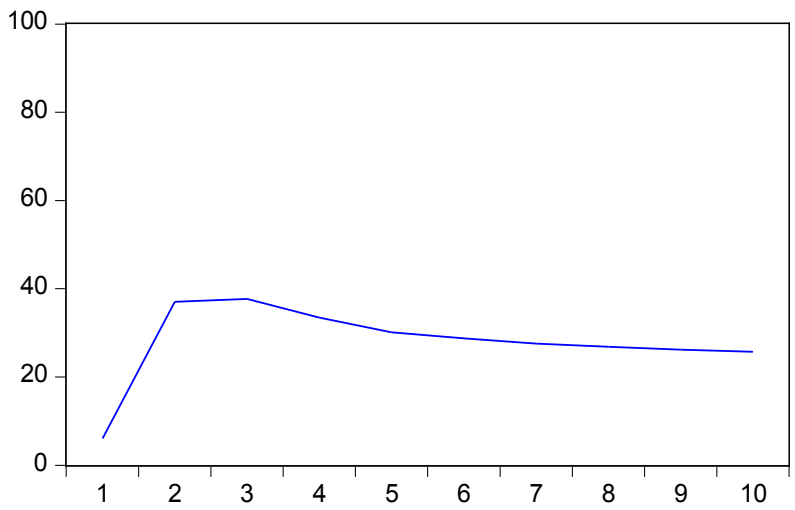

Figure 11. Variance decomposition of LNT of the Pearl River Delta.

cargo throughput $(\mathrm{T})$ increased from $12 \%$ to $53 \%$ in the first two periods, but declined sharply from the third period and finally stabilized around $16 \%$. As can be seen from Figure 11, the contribution of GDP to port cargo throughput (T) in the Pearl River Delta decreased from $80 \%$ to $43 \%$ in the first two periods, but it began to increase from the third period, and finally it is close to $60 \%$, while the contribution of industrial output (I) to port cargo throughput increased from $6 \%$ to $38 \%$ in the first two periods, but it decreased weakly from the third period and finally stabilized around $26 \%$.

\subsubsection{The Impact of Port Development on Urban Economy Development} The results of variance decomposition of LNGDP and LNI of the Yangtze River Delta and the Pearl River Delta are shown in Figure 12 and Figure 13 respectively.

As can be seen from Figure 12, port cargo throughput (T) has maintained a low contribution (less than 7\%) to GDP and industrial output over the study period for the Yangtze River Delta. In contrast, in the Pearl River Delta, the contribution of port cargo throughput (T) to port city GDP increased from 0 to $8 \%$ in the first two periods, and gradually stabilized around $10 \%$ from the third period. And the contribution of port cargo throughput (T) to industrial output (I) 
Variance Decomposition

Percent LNGDP variance due to LNT

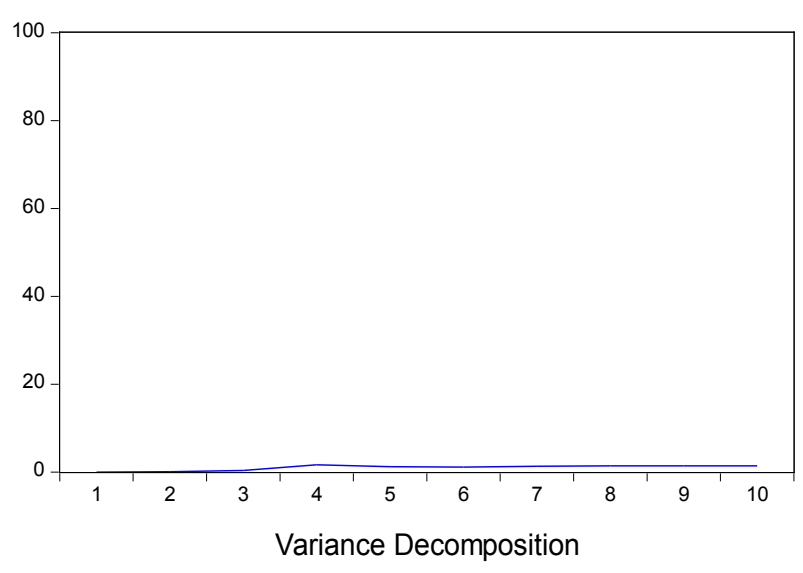

Percent LNI variance due to LNT

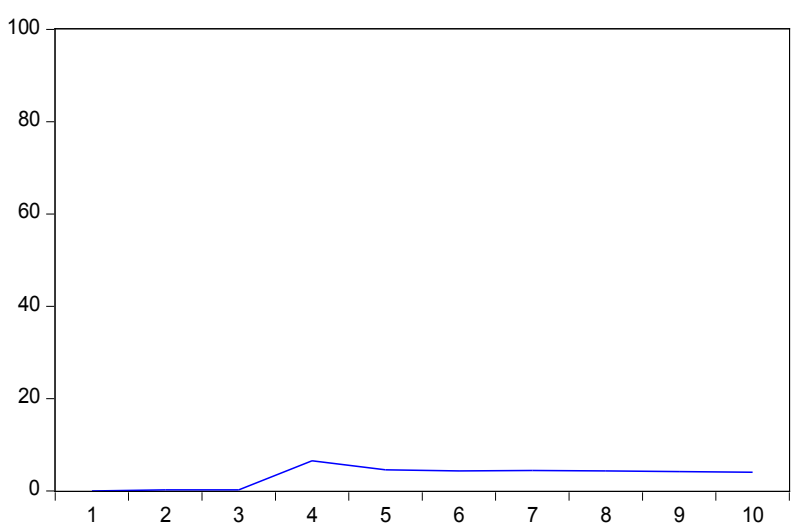

Figure 12. Variance decomposition of LNGDP and LNI of the Yangtze River Delta.

increased from 0 to $19 \%$ in the first two periods, and gradually stabilized at around $19 \%$ of the contribution.

Overall, both in the Yangtze River Delta and the Pearl River Delta, GDP and industrial output have high contribution to the port cargo throughput, and the contribution of GDP is slightly higher than the contribution of industrial output. The port cargo throughput in the Yangtze River Delta has little contribution to the growth of GDP and industrial output, while in the Pearl River Delta, and port cargo throughput has a certain contribution to GDP and industrial output. This result is consistent with the result of the impulse response graph.

\section{Concluding Remarks}

In this paper, we measure the relative size of port to the size of urban economy through improved relative concentration index (RCI), and the results show that the port-city relationship of the Yangtze River Delta is approaching coordination in the past ten years, while the port-city relationship of the Pearl River Delta is still in a state of incoordination, but it has begun to show the trend of coordination. In general, due to the favorable geographical conditions of the Yangtze River Delta, the economy is more developed, and the port system is more perfect, 
Variance Decomposition

Percent LNGDP variance due to LNT

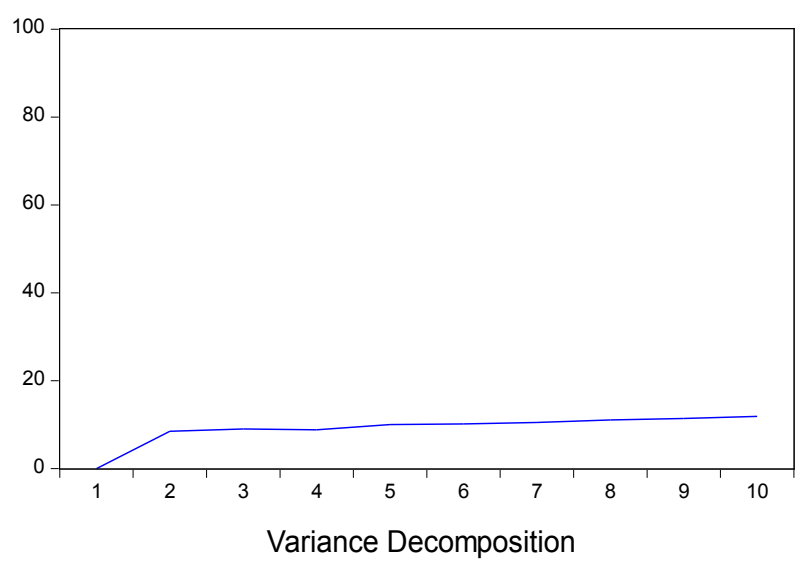

Percent $L N I$ variance due to $L N T$

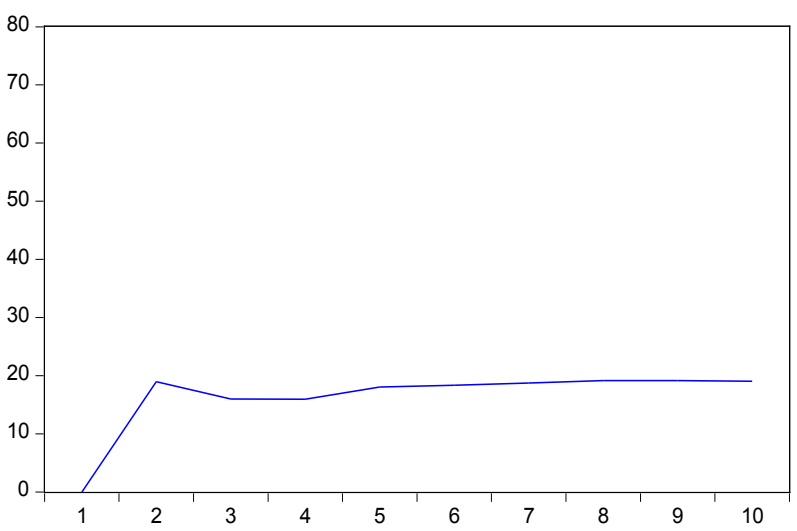

Figure 13. Variance decomposition of LNGDP and LNI of the Pearl River Delta.

and the economy hinterland is also more open, and the port-city relationship of the Yangtze River Delta is more coordinated than the Pearl River Delta.

In order to analyze the specific relevance between the port system and the urban economy system, we measure the port-city relationship of major port cities of the two major port groups by the gray relational analysis method. We found that GDP and industrial output have high relationship with the port cargo throughput, which indicates that port development is highly related to the city's GDP and industry. Therefore, the port needs to determine its speed of development according to the scale of its urban economy and industry. Whereas, the financial industry, fixed asset investment and foreign trade do not have high relationship with port development. The correlation coefficient in the Yangtze River Delta is higher than that of the Pearl River Delta, which indicates that the port-city connection of the Yangtze River Delta is closer.

Based on the gray relational analysis, the dynamic influence mechanism of GDP and industrial output with port cargo throughput is studied by impulse response analysis. The results show that GDP and industrial output have obvious positive effects on the development of the port development in the short term. Therefore, the port construction needs to cooperate with the development of 
urban economy so as to fully absorb the demand created by urban economy. The effect in the Yangtze River Delta is higher than that in the Pearl River Delta, so port city in the Yangtze River Delta needs to pay more attention to the construction of port facilities. On the other hand, the development of the port has small effect on GDP and industrial output, indicating that the current port-city interaction mechanism is mainly unilateral.

Although the port development has small effect on GDP and industrial output, we found that in the Pearl River Delta port development has a certain role in promoting urban economy and industry by variance diagram, that is mainly because the Pearl River Delta has higher dependence on foreign trade, then the development of the port can effectively promote the development of foreign trade of the city, which finally affects urban economy and industry. Therefore, port development needs to consider the economic type of its city, for city with more foreign trade; it needs to pay more attention to port development.

We have studied the port-city relationship of the port cities in the Yangtze River Delta and the Pearl River Delta, but China has many port cities, so the sample needs to be expanded in the future research. What's more, the specific impact mechanism is not studied in this paper, which is worth to be studied in the future.

\section{References}

[1] Vallega, A. (1979) Fonctions portuaires et polarisations littorales dans la nouvelle régionalisation de la Méditerranée, quelques réflexions. Villes et ports, développement portuaire, croissance spatiale des villes, environnement littoral, 355-367.

[2] Clozier, R. and Vigarié, A. (1968) Géographie de la circulation. Génin.

[3] Kenyon, J.B. (1970) Elements in Inter-Port Competition in the United States. Economic Geography, 46, 1-24. https://doi.org/10.2307/142680

[4] Chen, H. (2009) Research on Theory and Empirical for Interaction between Ports and Cities. Doctoral Dissertations, Dalian Maritime University, Dalian.

[5] Murphey, R. (1989) On the Evolution of the Port City. Brides of the Sea: Port Cities of Asia from the 16th - 20th Centuries. University of Hawaii Press, Honolulu, 223245.

[6] Hoyle, B. (2000) Global and Local Change on the Port-City Waterfront. Geographical Review, 90, 395-417. https://doi.org/10.2307/3250860

[7] Ducruet, C. and Lee, S.W. (2006) Frontline Soldiers of Globalisation: Port-City Evolution and Regional Competition. Geojournal, 67, 107-122.

https://doi.org/10.1007/s10708-006-9037-9 
Submit or recommend next manuscript to SCIRP and we will provide best service for you:

Accepting pre-submission inquiries through Email, Facebook, LinkedIn, Twitter, etc. A wide selection of journals (inclusive of 9 subjects, more than 200 journals)

Providing 24-hour high-quality service

User-friendly online submission system

Fair and swift peer-review system

Efficient typesetting and proofreading procedure

Display of the result of downloads and visits, as well as the number of cited articles Maximum dissemination of your research work

Submit your manuscript at: http://papersubmission.scirp.org/

Or contact jss@scirp.org 